\title{
Feasibility Investigation of Gears Manufactured by Fused Filament Fabrication
}

\author{
Hans-Jörg Dennig [0000-0002-2541-6147], Livia Zumofen ${ }^{10000-0002-2868-5254]}$, Andreas Kirch- \\ heim $^{1}$ \\ ${ }^{1}$ ZHAW Zurich University of Applied Sciences, ZPP Centre for Product and Process Devel- \\ opment, Winterthur, Switzerland
}

\begin{abstract}
.
This paper describes the production, quality and tests of plastic gears made by fused filament fabrication (FFF). Different 3D printers of low and high quality and four different materials were tested: PLA, ABS, PA and PA carbon fiber composite. After optimizing the print parameters, various gears were manufactured and tested. The geometry and the test procedure were executed based on the VDI 2736 standard. This paper is a feasibility study of the fatigue strength of different gears. There is no material data set for the specific FFF-Materials and certain printers.

The results show, that the quality of the printing process and the accuracy of the geometry are not responsible for the failure mode. The most important parameter is the friction coefficient of the different materials. Due to friction the tooth root will heat up and effect the material properties. PLA gears failed due to the low melting temperature, whereas ABS and PA gears failed on tooth root fracture.
\end{abstract}

Keywords: Gears, Fused Filament Fabrication, Testing, Additive Manufacturing, VDI 2736

\section{Introduction}

The use of additive manufacturing in the field of gears, for example for the production of metal gears with internal cooling systems is becoming increasingly important [1], [2]. More and more gears can also be produced in the field of additive manufacturing of plastic gears [3]. Precise and durable materials are produced here using selective laser sintering. These components can now be regarded as reliable and can exceed the fatigue strength of injection moulded Polyoxymethylene (POM) wheels.

FFF $^{1}$ manufactured gears (Fig. 1) made of Polylactide (PLA) or AcrylnitrilButadien-Styrol-Copolymere (ABS) are not associated with high strength or precision

1 Fused filament fabrication (FFF) is an extrusion process that presses a heated thermoplastic material, preferably continuously, through a nozzle and deposits the resulting strand in a defined manner on a substrate. To create contours, the extrusion nozzles are moved accordingly in the construction plane $(\mathrm{x}, \mathrm{y})[4]$. 
and are only used for low-stressed components and mock-ups for gears. Datasheets for gear transmission detailed FFF-Material characteristics, the influence of print parameters and on fatigue is unknown.

In this study, gears made of different available materials were manufactured on different printers with different printing parameters and tested on a gear test bench. The geometry and the test are based on the current European gear standard VDI 2736.

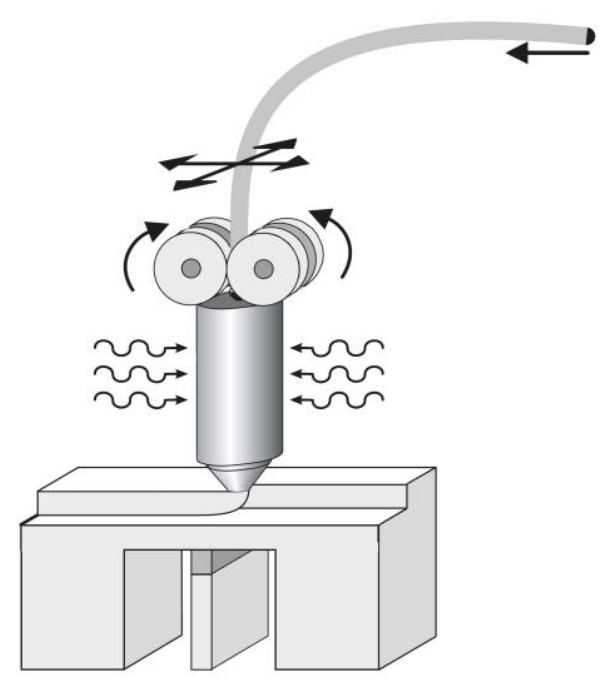

Fig. 1. Fused Filament Fabrication (FFF)-Process [4]

\section{Failure Mode of Plastic Gears}

Due to the cost-effective production of gears in the hobbing process, the involute shape of the teeth has become historically accepted. However, with the possibilities of additive manufacturing, numerous other shapes are conceivable, for example, ones optimized for ventilation loss or flank contact efficiency. But, the design and modelling of all current calculation literature, standards and software is based on the involute shape. That's why, the involute shape is used in the following investigation. The tooth in plastic gears can fail in different ways [5], [6]. Fig. 2 shows the important failure modes patterns. The following applies:

- Melting: The melting temperature of the material at the teeth is exceeded; more heat is added than dissipated. The teeth temperature rises steadily. Due to the temperature increase in the plastic teeth, the mechanical strength decreases continuously until it is too low for the transmission of force. The teeth soften or pushed away within a very short time. 
- Tooth root fracture: The bending stress is too high at the tooth root: If the bending strength of the plastic tooth is too low, bending fracture occurs outside the wear channel, where the flank does not come into contact with the opposite flank.

- Deformation: This occurs in both static and dynamic cases: Static: Deformation is caused by the flow of the material. The long-term modulus of elasticity is exceeded when a static load is applied. Dynamic: The short-term modulus of elasticity is exceeded. In both cases, the tooth head play is reduced and can lead to clamping of the gear stage.

- Delamination: The laminates created in the production process separate due to the excessive tangential force on the tooth flank. Additionally, the temperature at the tooth flank can exceed the melting temperature of the matrix, which can also cause delamination.

- Pitting: Hertzian pressure is too high with superimposed shear stress; pitting is the result of material fatigue in the near-surface area. The pitting is also caused by the shear stresses and the thermal stresses due to the sliding of the flanks [7].

- High wear: Low wear resistance or a highly abrasive surface of the friction partner; caused in part by chipping and in part by abrasion. This is especially the case on the tooth root and head, where the highest sliding speed occurs. Wear when mating the same plastics with each other is particularly high, especially on gears reinforced with short fibres.

- Tooth fracture on the flank: Crack formation due to Hertzian pressure and shear stresses at the wear zone, the crack grows into a fracture due to the bending stress.
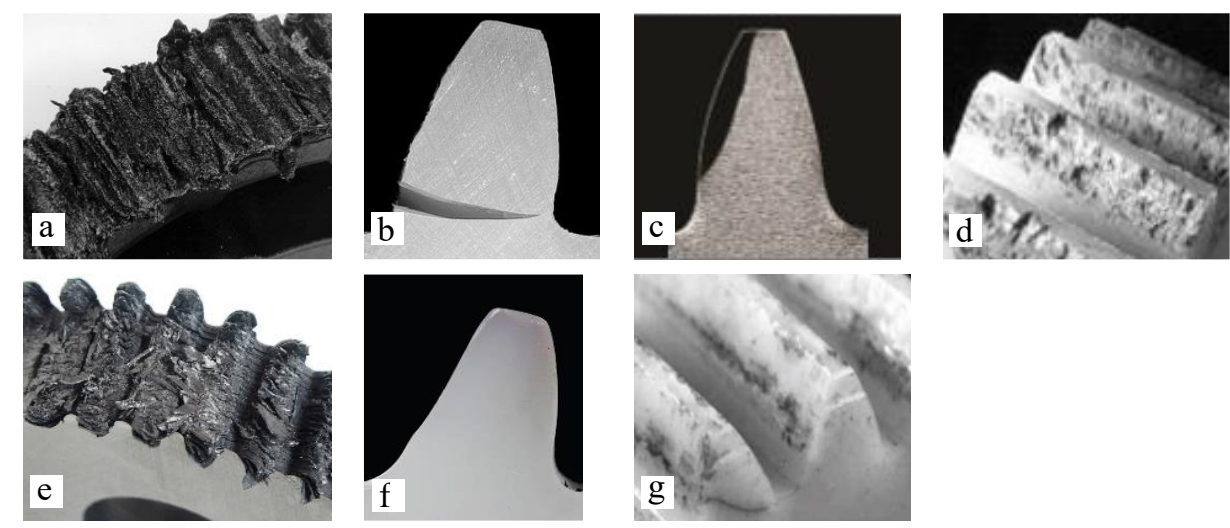

Fig. 2. Potential modes of failure for plastic gears (according to [5], [6], [7]): a-Melting, b-tooth root fracture, c-wear, d-pitting, e-delamination, f-deformation, g- tooth fracture on the flank

The design of plastic gears, especially in Europe, is based on VDI guideline 2736 [6]. This compares the material-specific and temperature-dependent permissible tooth root stress $\sigma_{\text {Flim }}$ based on a Woehler-curve with the stress $\sigma_{\mathrm{F}}$ that occurs. In addition, the wear coefficient $\mathrm{k}_{\mathrm{w}}$ is calculated based on tooth flank distance before and after the tests. 
To determine fatigue strength under pulsating stress $\sigma_{\text {Flim }}$ (equation 1$)^{2}$ the number of load cycles before tooth fracture are counted [8]: $b=$ face width, $F_{t}=$ nominal tangential force, $\mathrm{m}_{\mathrm{n}}=$ normal module. The damage patterns of pitting and tooth fracture on the flank are more likely to occur with high-strength plastics such as Polyetheretherketon (PEEK). Therefore, the rolling contact-fatigue-strength $\sigma_{\mathrm{Hlim}}$ and thus the Hertzian stress will not be discussed further here.

$$
\sigma_{\mathrm{FlimN}}=Y_{F a} \cdot \frac{Y_{S a}}{Y_{S t}} \cdot Y_{\varepsilon} \cdot \frac{F_{t}}{b \cdot m_{n}}
$$

To determine wear coefficient $\mathrm{k}_{\mathrm{w}}$, wear is measured after a fixed number of rollovers $\mathrm{N}_{\mathrm{L}}$. In this investigation, the abrasion coefficient $\mathrm{k}_{\mathrm{w}}$ is calculated via the local linear wear $\mathrm{W}_{\text {lokal }}$ measured at the flank (equation. 2): $\mathrm{F}_{\mathrm{n}, \text { lokal }}=$ normal force on the tooth at the contact, $\zeta=$ local specific gliding.

$$
k_{w}=\frac{W_{\text {lokal }}}{N_{L}} \cdot \frac{b}{F_{n, l o k a l}} \cdot \frac{1}{\zeta}
$$

The limit for $\mathrm{W}_{\text {lokal }}$ is defined as $20 \%$ of the modul $\mathrm{m}_{\mathrm{n}}$.

The design of plastic gears, compared to steel gears, is generally challenging due to the temperature-dependent young's modulus. VDI 2736 describes the procedure for designing plastic gears and also contains specific material data. However, since plastics from different manufacturers have different material properties, despite having the same name, these specific properties or values rarely exist. In addition, there are different plastic compositions and so-called fiber additives that modify properties. In the field of additive manufacturing of plastic gears there are no reference values for a design.

Skawiński (et al.) [9] have investigated the effects of layer heights, layer structure and numerous other print parameters on resulting mechanical properties of gears. However, this was not on the basis of an involute form or with regard to a dynamic gear test. Thus, there are no published research results on FFF-printed and tested gears.

\section{Test Samples}

\subsection{Gearwheel Geometry}

The gear geometry of the FFF plastic gears is based on size 2 described in VDI 2736 Part 4 [8], which is slightly modified due to better tooth contact (Table 1). A feather key connection is used as wheel-hub connection Fig. 3.

2 The values for the Y-factors are defined in the [8]. 
Table 1. Gear dimensions

\begin{tabular}{|c|c|}
\hline Symbol $^{3}$ & Value (FFF-Gear; Steel-Gear) \\
\hline Centre Distance a & $60 \mathrm{~mm}$ \\
\hline Normal module $m_{n}$ & $2 \mathrm{~mm}$ \\
\hline Tooth number $\mathrm{z}_{1} ; \mathrm{z}_{2}$ & $31 ; 29$ \\
\hline Face width $b_{1} ; b_{2}$ & $8 \mathrm{~mm} ; 13 \mathrm{~mm}$ \\
\hline Tip diameter $d_{a 1 \max } ; d_{a 1 \min }$ & $66 \mathrm{~mm} ; 65.97 \mathrm{~mm}$ \\
\hline Tip diameter $\mathrm{d}_{\mathrm{a} 2 \max } ; \mathrm{d}_{\mathrm{a} 2 \min }$ & $62 \mathrm{~mm} ; 61.97 \mathrm{~mm}$ \\
\hline Root diameter $\mathrm{d}_{\mathrm{f} 1 \mathrm{max}} ; \mathrm{d}_{\mathrm{f} 1 \min }$ & $56.85 \mathrm{~mm} ; 56.75 \mathrm{~mm}$ \\
\hline Root diameter $\mathrm{d}_{\mathrm{f} 2 \max } ; \mathrm{d}_{\mathrm{f} 2 \min }$ & $52.9 \mathrm{~mm} ; 52.83 \mathrm{~mm}$ \\
\hline Tip rounding radius & $0 \mathrm{~mm} ; 0.6 \mathrm{~mm}$ \\
\hline Pressure angle $\alpha_{\mathrm{n}}$ & $20^{\circ}$ \\
\hline Helix angle $\beta$ & $0^{\circ}$ \\
\hline Addendum modification $\mathrm{x}_{1}, \mathrm{x}_{2}$ & $0 \mathrm{~mm}$ \\
\hline Tooth Quality & $>10 \mathrm{e}(\mathrm{DIN} 58405) ; 7$ (DIN 3961) \\
\hline $\mathrm{h}_{\mathrm{aP}}$ & 1 \\
\hline$h *_{\mathrm{fP}}$ & 1.25 \\
\hline$\rho *_{\mathrm{fP}}$ & 0.38 \\
\hline
\end{tabular}

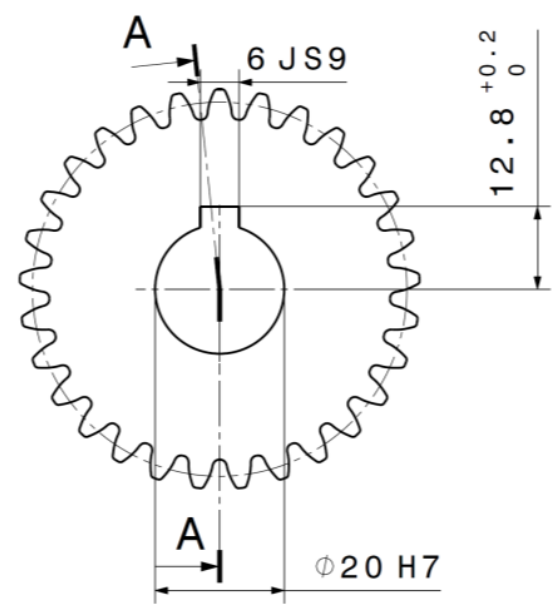

Fig. 3. Gear wheel geometry with feather key connection

\subsection{Material and Production}

All gears were printed horizontally without support structures (Fig. 4). This ensures that the contour lines are as precise as possible. In addition, there is no tensile stress between the layers in the area of the tooth root.

$3 \quad$ Index 1 = FFF-Gear; Index 2 = Steel gear 


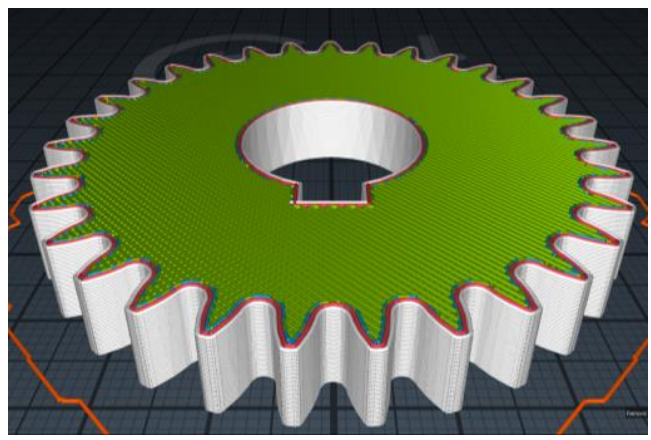

Fig. 4. Example of a Craftbot section in the slicing software

Three materials commonly used on FFF printers were examined: PLA, ABS and PA66 (Nylon) (Table 2, Table 3). With PA66, it is possible to integrate endless carbon fibers in the printing process: The Markforged dual printer Mark two, which can process various additional materials to reinforce components via a fiber feed. For this reason, the material PA66 was additionally processed with endless reinforced carbon fibres $(\mathrm{PA} 66+\mathrm{CF})$. The Craftbot + printer is a low-cost PLA printer that has very good quality results in its price segment. This compares to the professional ABS printer from Stratasys F270.

The gear geometry from Table 1 is printed with the settings shown in Table 3. A comparison of the print results is shown in Fig. 5.

Table 2. Overview of materials

(the values are based on the information provided by material suppliers)

\begin{tabular}{l|l|l|l}
\hline Material & $\begin{array}{l}\text { Tensile/Flexural } \\
\text { strength at yield } / \mathrm{MPa}\end{array}$ & $\begin{array}{l}\text { Youg modulus } \\
/ \mathrm{MPa}\end{array}$ & $\begin{array}{l}\text { Heat deflection } \\
\text { temp. } /{ }^{\circ} \mathrm{C}\end{array}$ \\
\hline PLA [10] & $26 / 45$ & 2539 & 63 \\
\hline ABS (plus-P430) [11] & $31 / 35$ & 2200 & 96 \\
\hline PA [12] & $-/ 51$ & 1700 & 41 \\
\hline PA+CF [12] & $-/ 540$ & 60000 & 105 \\
\hline
\end{tabular}

Table 3. Printers and print parameters used

\begin{tabular}{l|l|l|l|l|l|l}
\hline Material & Printer & $\begin{array}{l}\text { Extr.width } \\
/ \mathrm{mm}\end{array}$ & $\begin{array}{l}\text { Layer h. } \\
\text { /mm }\end{array}$ & $\begin{array}{l}\text { Contour } \\
\text { lines }\end{array}$ & $\begin{array}{l}\text { Top/Bo. } \\
\text { layers }\end{array}$ & Infill \\
\hline PLA & Craftbot + & 0.4 & 0.2 & 2 & 4 & $75 \%$ \\
\hline ABS & Stratasys F270 & 0.3556 & 0.25 & 2 & 2 & $22 \%$ \\
\hline PA & $\begin{array}{l}\text { Markforged } \\
\text { PA+CF }\end{array}$ & 0.4 & 0.125 & 2 & 4 & $37 \%$ \\
\hline
\end{tabular}



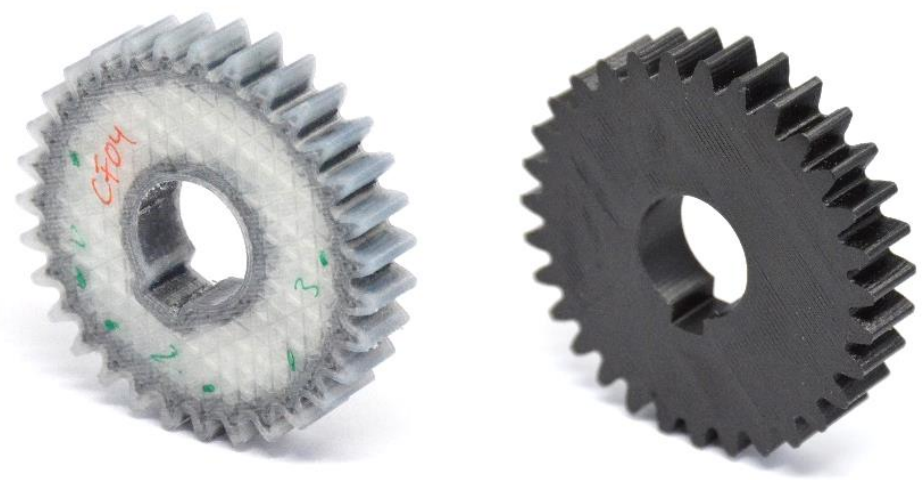

Fig. 5. Printed gear wheel examples PA66+CF (left) and PLA (right)

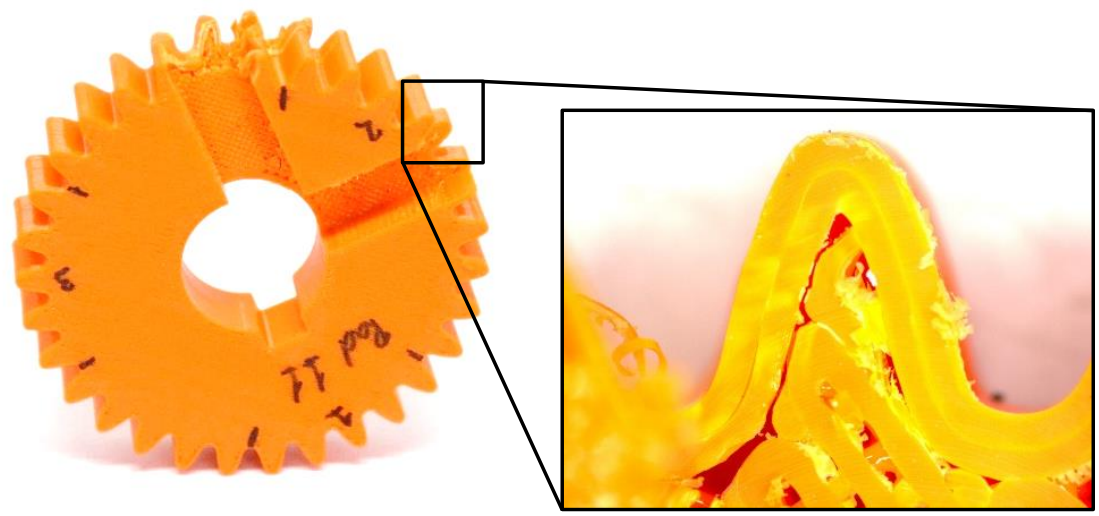

Fig. 6. Section view of a ABS-Gear with two contour lines.

\section{Quality}

Fig. 7 shows the flank of different printed gears with various layer resolutions. A striking feature of ABS and PA66 is the so-called wrapping. All the gears were printed without raft. Also pictured is the so-called oozing on the flank surface of PA66 $+\mathrm{CF}$, which is due to the different materials PA and CF. However, the quality of the surfaces can be rated as very good for all materials after several optimization loops of the printing parameters. 


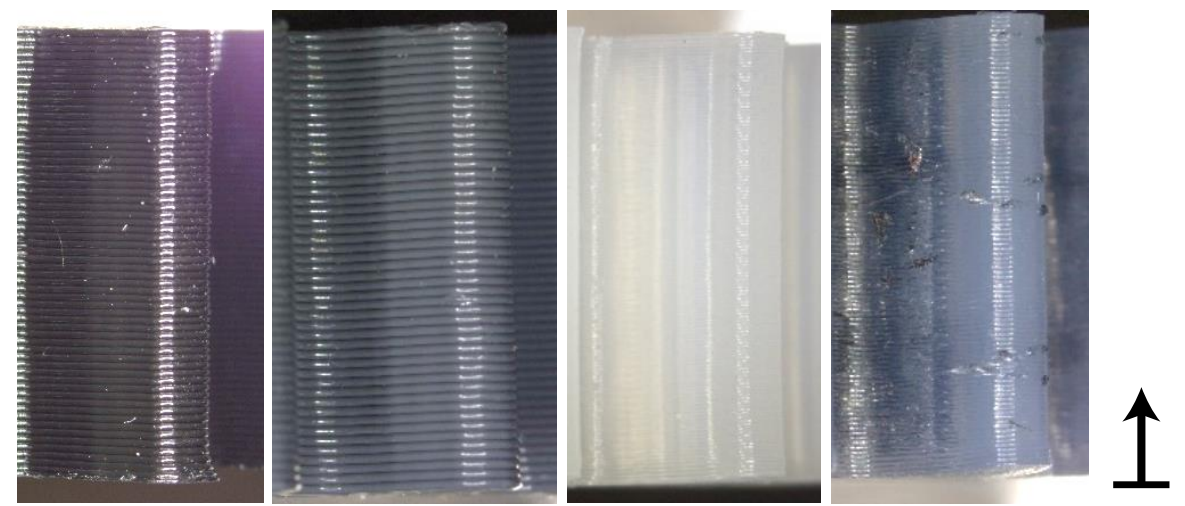

Fig. 7. Flank of different gears: PLA, ABS, PA, PA+CF (from left to right), $z=$ vertical printing axis
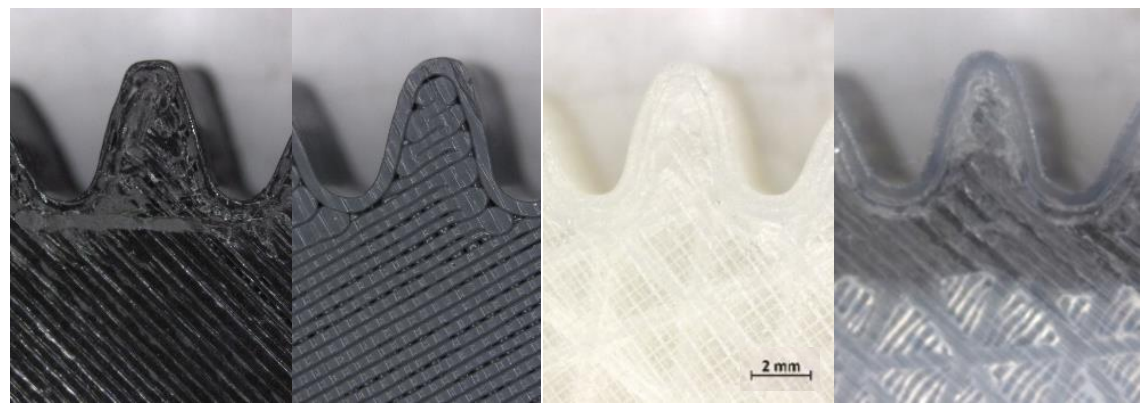

Fig. 8. Top-Layer: Printing results of the gears: PLA, ABS, PA, PA+CF (from left to right)

All the wheels were analysed on a double-flank rolling test device (Fig. 9). The results indicate the base tangent length, the tooth-to-tooth error and, in particular, the concentricity.

According to DIN 3960, the tooth width $\mathrm{W}_{\mathrm{k}}$ was measured with a disc-micrometer at three different positions (Fig. 9) and can be compared to the values as in Table 1. 


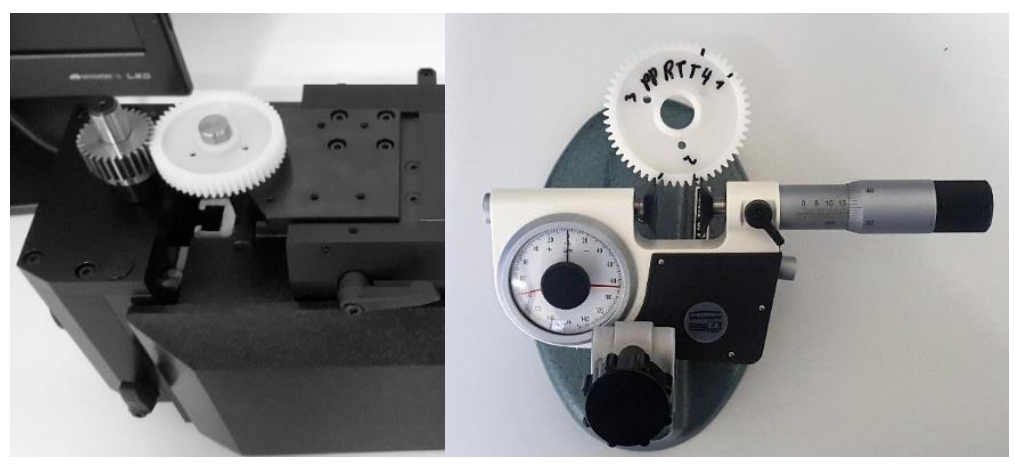

Fig. 9. Double flank gear tester (left), disc micrometer (right)

The quality of plastic gears is defined in the DIN standard 58405. This standard can be set in the software of the double flank gear tester. Injection-moulded plastic gears made of POM, for example, have a standard quality of 8 to 10 (out of 12, whereas 1 is the best). However, this quality can only be achieved by complex tool optimisation. Concentricity is a particularly important factor here. Poor concentricity leads to local high pressure on the tooth flank, which in turn leads to increased temperatures in dynamic operation. Table 4 shows the measurement results of the gears. At least three wheels for each material were measured.

As expected, the values of all the printed gears were outside the standard. The high-quality Stratasys printer showed the best geometrical results, followed by the low-cost Craftbot printer.

Table 4. Measurement results from double flank gear tested and disc micrometre: $\mathrm{W}_{\mathrm{k} 1}=$ base tangent length, Fr" = the roundness, fi' " = the tooth to tooth error; Quality 10e SET

\begin{tabular}{|c|c|c|c|c|c|c|c|}
\hline $\begin{array}{l}\text { all values } \\
\text { in } \mathrm{mm}\end{array}$ & $\begin{array}{l}\text { Fr" } \\
\text { ACTUAL }\end{array}$ & $\begin{array}{l}\mathrm{Fr}^{\prime \prime} \\
\text { SET }\end{array}$ & $\begin{array}{l}\text { St. Deviation } \\
\text { Fr" }\end{array}$ & $\begin{array}{l}\text { fi" } \\
\text { ACTUAL }\end{array}$ & $\begin{array}{l}\text { fi" } \\
\text { SET }\end{array}$ & $\begin{array}{l}\mathrm{W}_{\mathrm{k} 1} \\
\text { ACTUAL }\end{array}$ & $\begin{array}{l}\mathrm{W}_{\mathrm{k} 1} \mathrm{SET} \\
(\max -\min )\end{array}$ \\
\hline PLA & 0.264 & \multirow{4}{*}{0.052} & 0.081 & 0.263 & \multirow{4}{*}{0.037} & 27.161 & \multirow{4}{*}{$\begin{array}{c}27.337- \\
27.269\end{array}$} \\
\hline ABS & 0.128 & & 0.047 & 0.128 & & 27.356 & \\
\hline PA & 0.405 & & 0.113 & 0.405 & & 27.120 & \\
\hline $\mathrm{PA}+\mathrm{CF}$ & 0.674 & & 0.125 & 0.674 & & 27.477 & \\
\hline
\end{tabular}

Based on the measurement in Table 4, the tolerances of the steel counter gear can be defined and the steel gear can be produced. The tolerance adjustment on the steel wheel prevents the gear pair from jamming. The steel counter gear was manufactured on a DMG Mori NTX 2000sz turning/milling centre with Euklid software. 


\section{$5 \quad$ Test}

\section{$5.1 \quad$ Test Rig}

The test setup is a non-mechanical closed loop test rig (Fig. 10, Fig. 11). The investigations were executed in the combination between gear 1 (plastic) and gear 2 (steel) and with a centre distance of $60 \mathrm{~mm}$ (also Table 1). Gear 1 is the driving gear. All tests were driven in dry condition.

To calculate the material properties, the temperature to be evaluated was taken at almost the end of the investigation cycle. The tooth flank / surface temperature $\mathrm{T}_{\mathrm{S}}$ and the body temperature $\mathrm{T}_{\mathrm{B}}$ during operation were measured with a thermal infrared camera (Fig. 12). $\mathrm{T}_{\mathrm{B}}$ can be regarded as equivalent to the temperature of the tooth root. The room temperature $\mathrm{T}_{\mathrm{U}}$ is controlled by a sensor closed to the gears, so that the $T_{B}$ stays constant depending on the induced power.

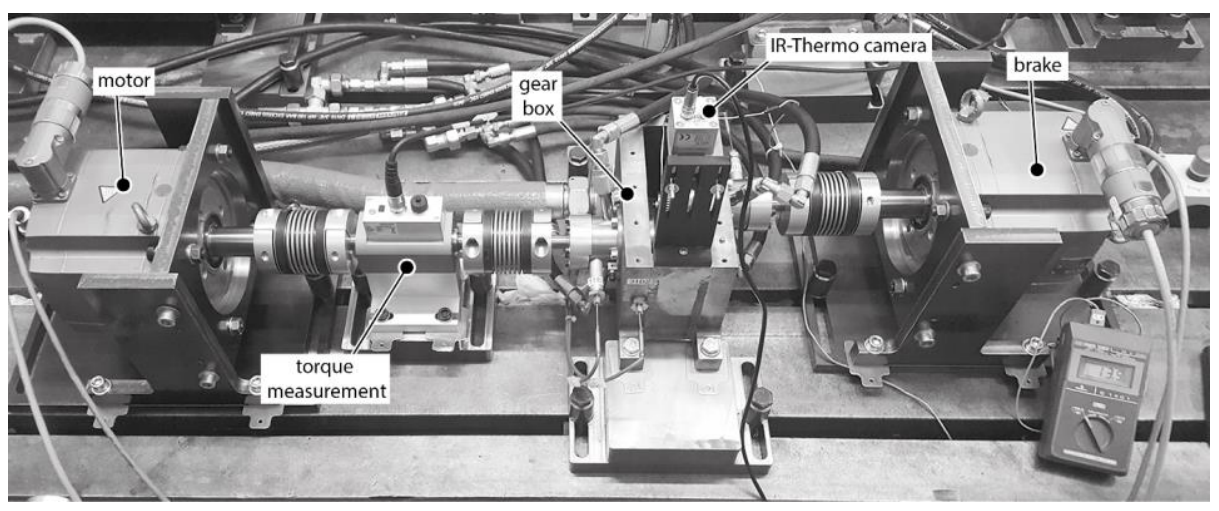

Fig. 10. Plastic gear test rig

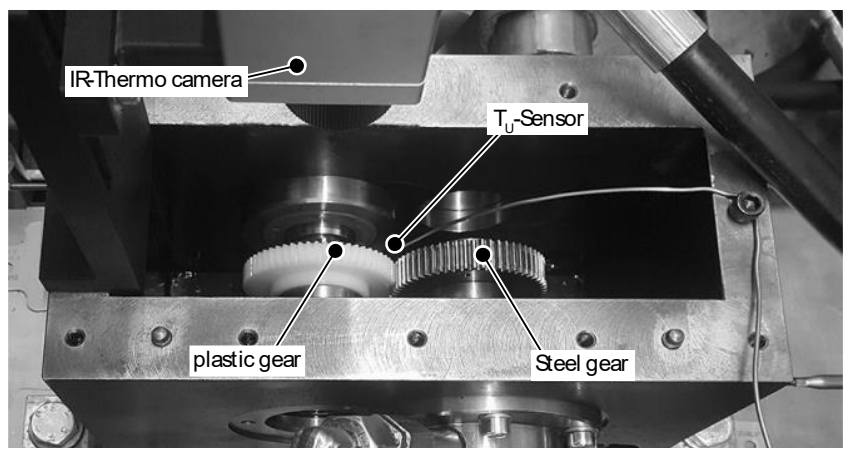

Fig. 11. Gearbox 

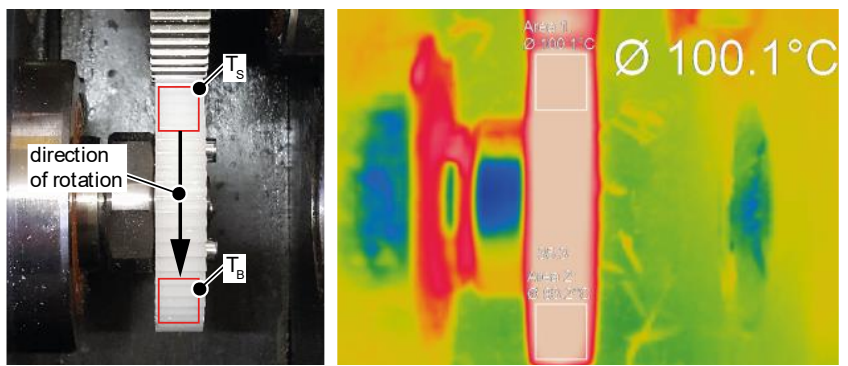

Fig. 12. Principle of the temperature measurement

All test results were evaluated according to the specifications of VDI 2736 Part 4.

At least three gears per load were tested. At 1 or $2 \cdot 10^{6}$ load cycles respectively the test was aborted. At pre-determined intervals inspection for possible damage (pitting, tooth fracture) was carried out. Once the type of damage was defined, the torque value of the further tests was selected depending on the number of load cycles to be run. The drive speed was always $1500 \mathrm{~min}^{-1}$. The plastic gears were not conditioned, but were tested within three days of manufacture.

\subsection{Results}

Fig. 13 shows the results of the fatigue tests. The incoming torque $\mathrm{T}_{\mathrm{an}}$ is converted to a tooth root stress $\sigma_{\mathrm{F}}$ via the pitch circle and the gear width, as in equation (1). This allows comparisons to be made with other research results.

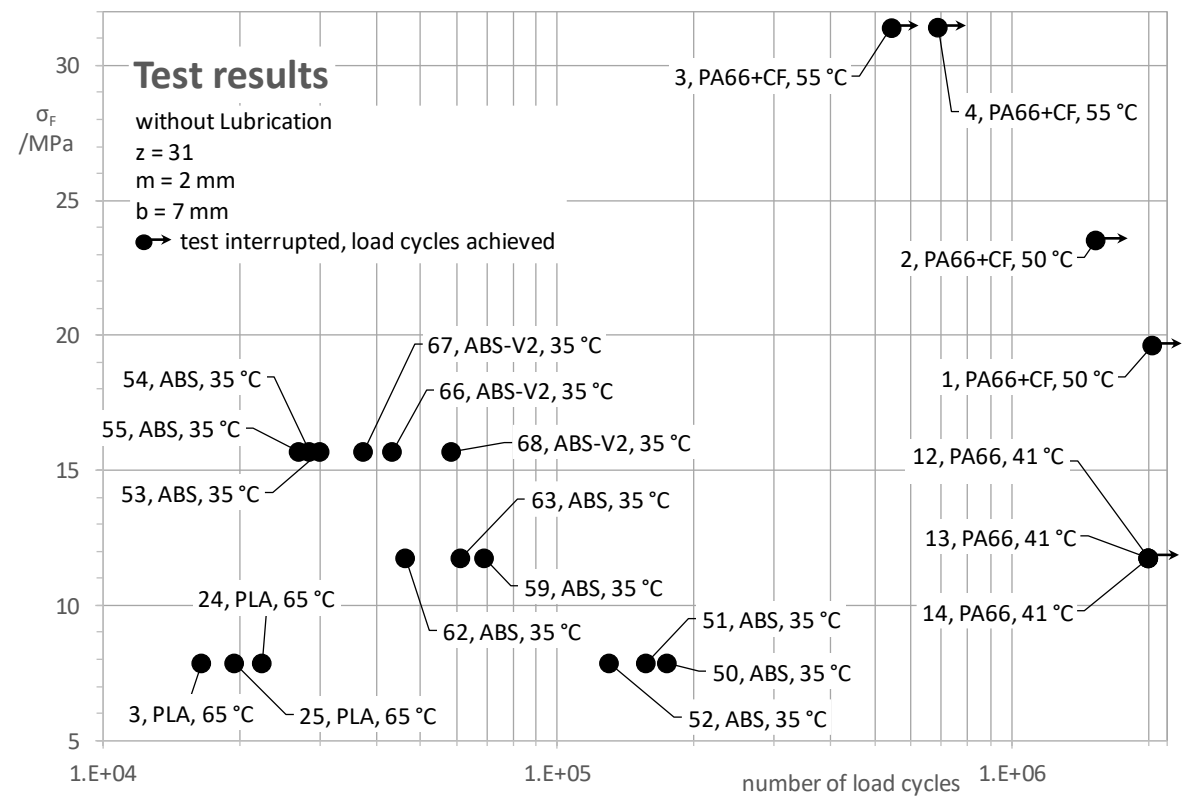

Fig. 13. Result diagram of the fatigue test 
For certain gears, the tooth width was measured after a pre-determined number of cycles and based on this, the wear coefficient was determined according to formula (2) (Table 5).

Table 5. Wear results

\begin{tabular}{|c|c|c|c|c|c|c|c|}
\hline & ABS-1 & ABS-2 & ABS-3 & $\begin{array}{c}\text { PA66 - } \\
1\end{array}$ & $\begin{array}{l}\text { PA66 - } \\
2\end{array}$ & $\begin{array}{l}\text { PA66- } \\
\text { CF-1 }\end{array}$ & $\begin{array}{l}\text { PA66- } \\
\text { CF-2 }\end{array}$ \\
\hline$F_{n, \text { Lokal }} / \mathrm{N}$ & 51.4 & 51.4 & 51.4 & 51.4 & 51.4 & 85.7 & 102.9 \\
\hline$\zeta$ & \multicolumn{7}{|c|}{0.1578} \\
\hline $\mathrm{W}_{\text {lokal }} / \mathrm{mm}$ & 0.11 & 0.10 & 0.11 & 0.01 & 0.02 & 0.06 & 0.10 \\
\hline $\mathrm{N}_{\mathrm{L}}$ & 157500 & 175000 & 130000 & 2008500 & 2008500 & 2008500 & 2041500 \\
\hline $\begin{array}{c}\varnothing-\mathrm{k}_{\mathrm{w}} / \\
\mathrm{mm}^{3} / \mathrm{Nm} / 10^{6}\end{array}$ & \multicolumn{3}{|c|}{1051.7} & \multicolumn{2}{|c|}{11.0} & \multicolumn{2}{|c|}{36.3} \\
\hline
\end{tabular}

After fatigue test and wear measurements, the following key statements can be made with respect to the load cycles:

PLA-Gears: The tooth root temperature $\mathrm{T}_{\mathrm{S}}$ exceeds the heat deflection temperature of $63{ }^{\circ} \mathrm{C}$ during the measurements. This causes the teeth to melt away. PLA wheels thus fail on melting (Fig. 14). The filling structure therefore has no influence on the lifetime of the gear. The tooth flank temperature is responsible for this type of failure due to melting, and can only be changed by the accuracy of the teeth and the material. It is possible that the printed layer height effects the surface and thus the temperature. However, since the number of cycles was very small, no variations were carried out here. Measurements regarding wear could not be made because all the gears failed within a very short time. 

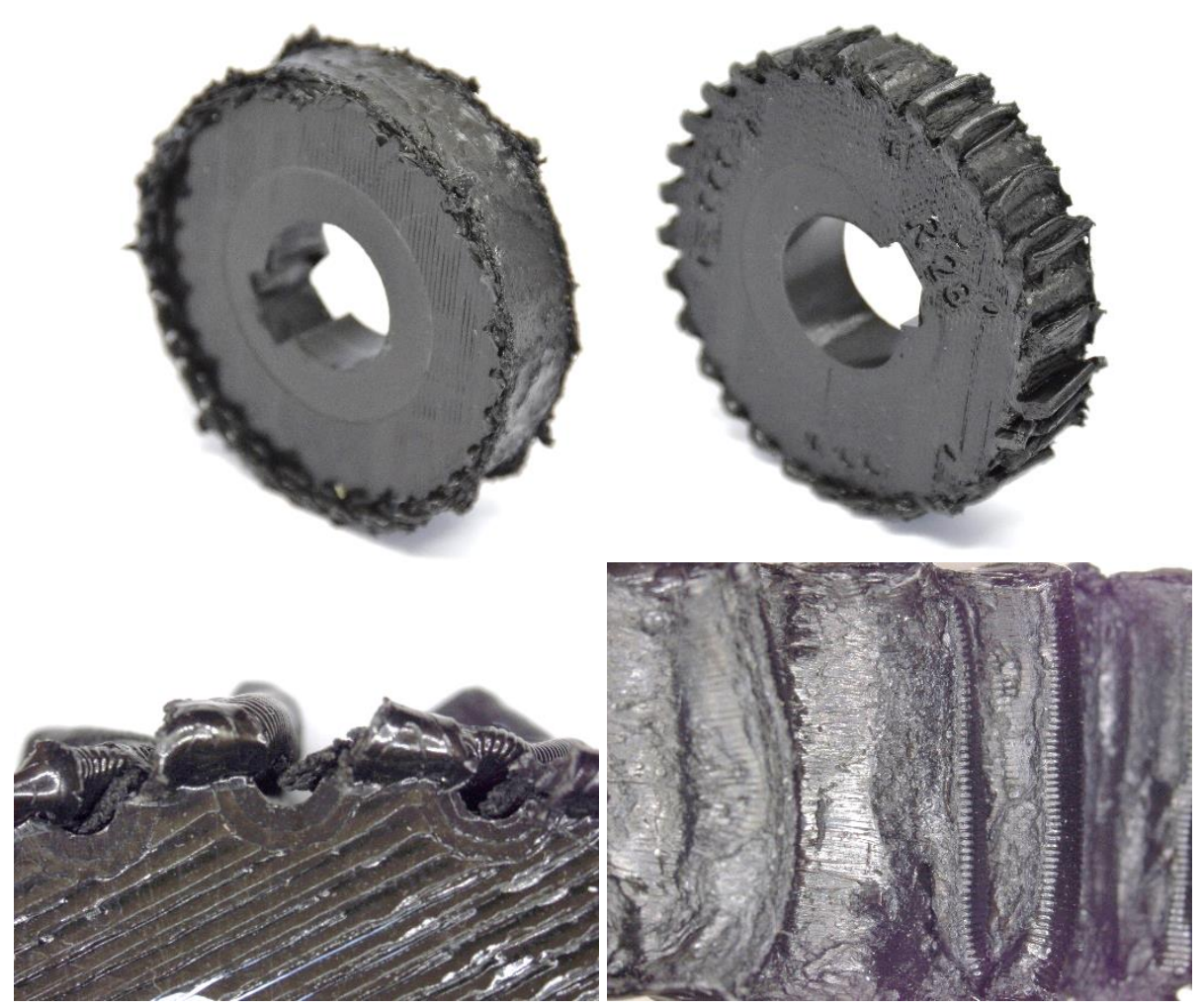

Fig. 14. PLA Gears with melted teeth

ABS-Gears: The tests with ABS gears were carried out with the steel counter wheel, which was specifically designed for the PLA wheels. The ABS gears failed at all measured torques owing to tooth-root fracture. The test rig cannot detect single tooth breakage, which is why several teeth were chipped off on some gears (Fig. 15). The tooth root temperature was around $35^{\circ} \mathrm{C}$ in all tests.

In further tests the number of outline layers was increased from two to four, which led to slightly higher cycle numbers under equal loads at approx. $\sigma_{\mathrm{F}}=16 \mathrm{MPa}$ (ABSV2 in Fig 13).

One noticeable result was the very high wear. It can be postulated that the print layers on the flanks are smoothed at the beginning of the tooth engagement, which causes the tooth form to be reduced more than through normal wear. The local wear $\mathrm{W}_{\text {lokal }}$ is determined by the tooth width before and after the test. $\mathrm{k}_{\mathrm{w}}$ is accordingly very high. 


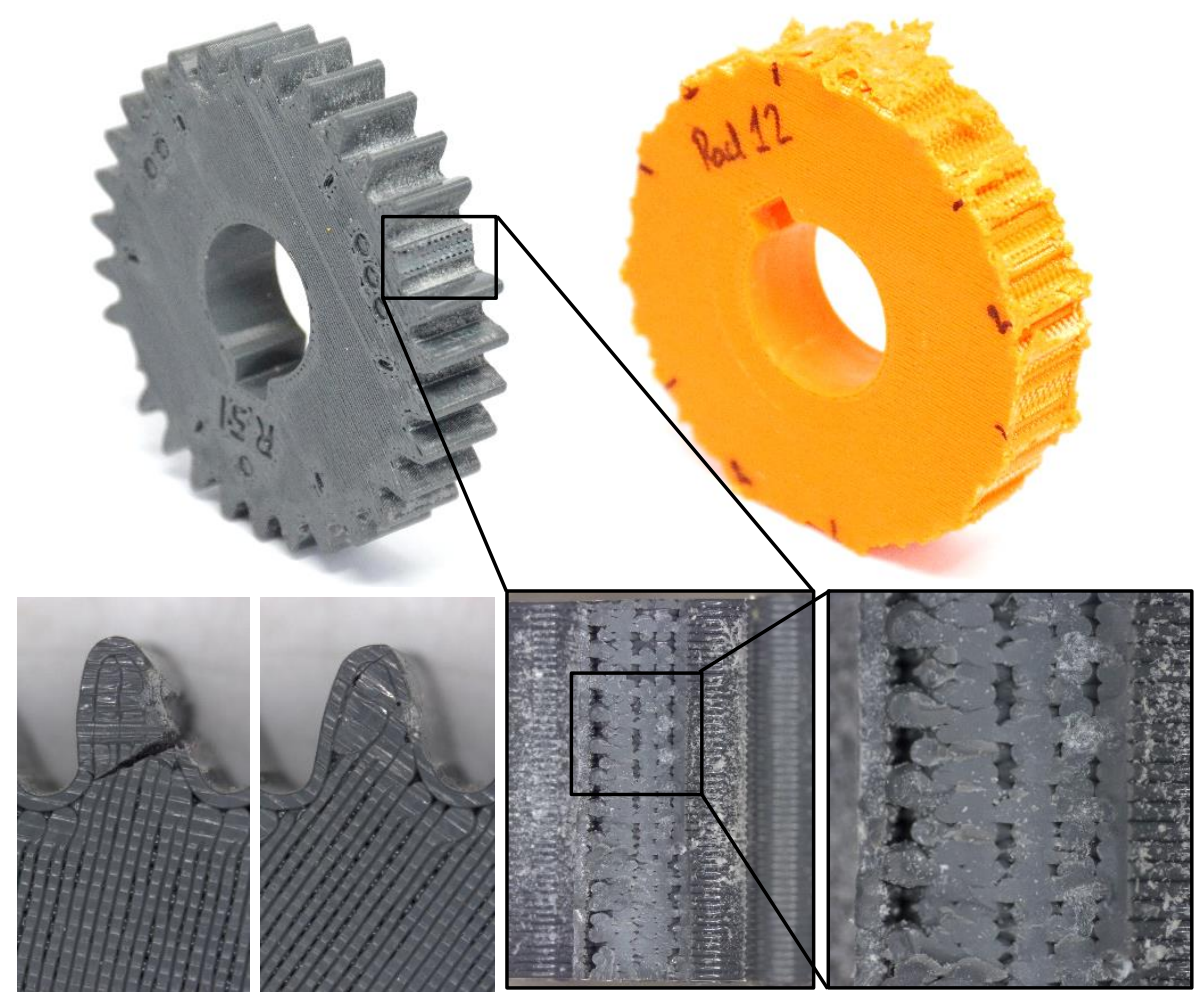

Fig. 15. ABS gears with broken teeth

PA66-Gears: The tests of PA66 gears were stopped after a maximum of 2 million cycles. Apart from signs of wear on the tooth flank, no damage was visible. The tooth root temperature was around $41{ }^{\circ} \mathrm{C}$ in all tests.

Here too, the wear is rather high in comparison to the usual wear values of $\mathrm{k}_{\mathrm{w}}=1$ $7.8 \mathrm{~mm}^{3} / \mathrm{Nm} / 10^{6}[8]$.

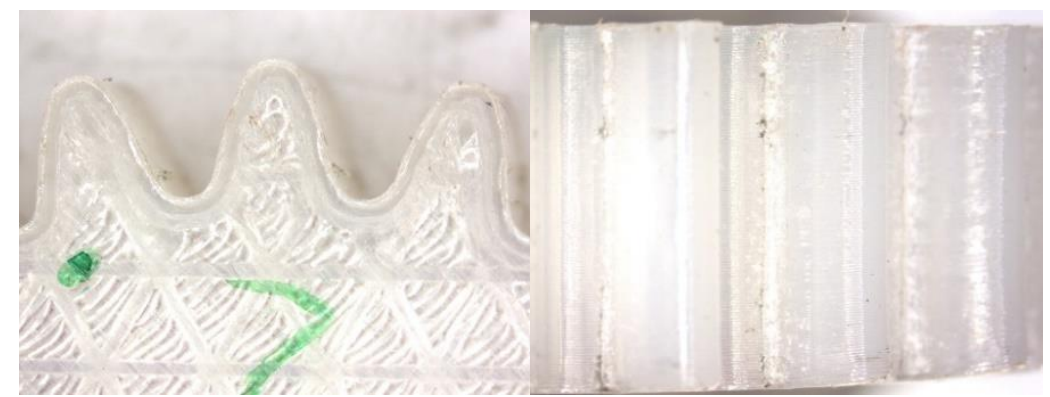

Fig. 16. PA66 gear after two Mio. cycles at a root stress $\sigma_{\mathrm{F}}=12 \mathrm{MPa}$ 
PA66-CF-Gears: The tests of PA66-CF gears were stopped after a maximum of 2 million cycles. Apart from signs of wear on the tooth flank, no damage was visible. Since the load and thus the tooth root stress was increased again, the temperatures rose up to $50{ }^{\circ} \mathrm{C}$. Above the tooth root stress of $\sigma_{\mathrm{F}}=23 \mathrm{MPa}$ the gear exceeded a temperature of approx. $60^{\circ} \mathrm{C}$ and began to deform plastically. The teeth were bent (Fig. 18).

In further tests, the tooth root load was increased to approx. $\sigma_{\mathrm{F}}=31 \mathrm{MPa}$, which caused the gears to fail (Fig. 18). However, it cannot be clearly determined whether this was due to melting or tooth root fracture.

Here too, the wear is rather high in comparison to the usual wear values of $\mathrm{k}_{\mathrm{w}}=1-7.8 \mathrm{~mm}^{3} / \mathrm{Nm} / 10^{6}[8]$.

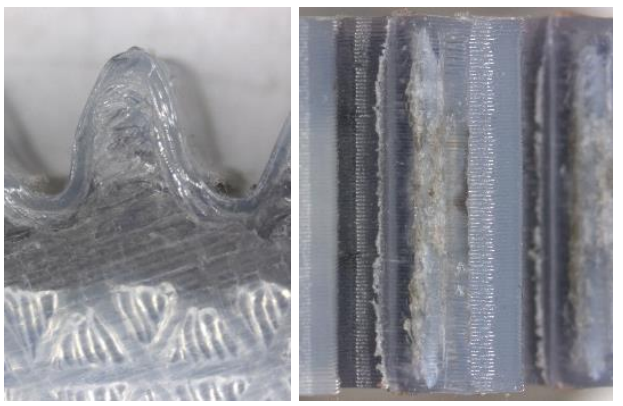

Fig. 17. PA66-CF gears with deformed teeth and wear on the flanks

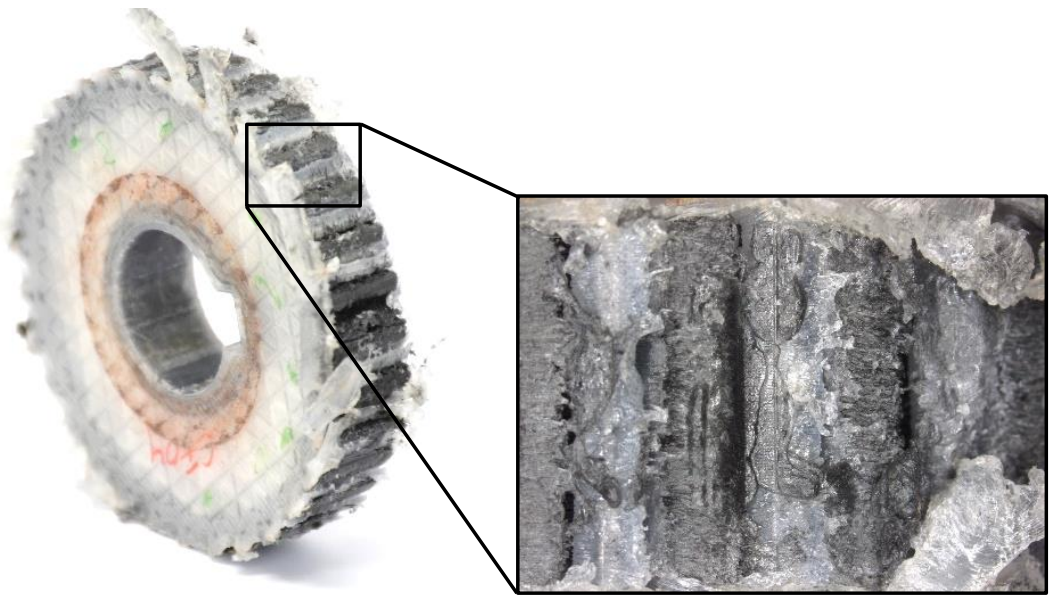

Fig. 18. PA66-CF gear with broken or melted teeth

\section{Conclusion}

The tests carried out provide a preliminary overview of the load capacity and use of additive manufactured gears made of PLA, ABS, PA66 and PA66+CF by the FFF 
process. It shows that gears made of PLA are not suitable due to the high heat generated by contact of the tooth flanks. While ABS gears can be used for low loads, gears made of PA66 achieve reasonable cycle times even with high tooth root stress. However, in order to be able to make reliable statements about the material properties in tooth contact, Woehler curves must be created at constant tooth root temperatures. Two Woehler curves at tooth root temperatures, set far apart, are sufficient.

Due to the heat deflection temperatures of the various thermoplastics, a sufficiently robust cooling system must be used. With current resources this can be done, for example, with nitrogen cooling, which is available on the above-mentioned test stand. The cooling must be controlled based on the heat generated at the tooth flank contact and measured by infrared camera.

All manufactured gears tend to be produced with larger outer diameters and smaller inner diameters at the wheel-hub connection. This means that the contour lines can be optimized to enable printers to produce standard-compliant gears. Results demonstrate, however, that although the geometric print quality is poor in comparison to injection-moulded gears, the number of load cycles achieved is high, especially with PA66. It can therefore be assumed that the flank properties with a rough surface have less of an influence than initially expected. Since ABS wheels fail on tooth breakage, an optimization of the number of outline layers lead to an increase in strength.

The numbers of cycles and the loads that were run with PA66-CF and PA66 were compared with values of injection moulded PA66 gears from the literature. Comparative values exist in the area of low loads. These show that the PA66-CF wheels certainly have similar cycle numbers compared to injection moulded PA66 gears. For higher ranges, in particular $\sigma_{\mathrm{F}}>10 \mathrm{MPa}$, it is not possible to compare them directly, as values for the tooth root temperature do not exist for the same loads. Therefore, tests with injection moulded PA66 gears need to be carried out and compared.

The wear values measured in the test cannot be compared with injection-moulded gears. It can be postulated that the print layers on the flanks are smoothed at the beginning of the tooth engagement. In order to obtain meaningful results, tooth width measurements must be taken during the tests: for example, after 100,000 and after $1,000,000$ cycles.

In further tests, the aim is to determine the characteristic curves of PA66 $(+\mathrm{CF})$ gears at different temperatures and to conduct wear measurements which provide valid results. These material characteristics can then be used in calculation software such as KISSsoft.

\section{References}

[1] C. Brecher, C. Löpenhaus, R. Greschert, R. Poprawe, J. H. Schleifenbaum, and D. Ziebura, 'Potenzial generativ gefertigter Bauteile in der Getriebetechnik', in Antriebstechnisches Kolloquium ATK 2019, Aachen, 2019, pp. 251-264.

[2] H.-J. Dennig and S. Winterberg, 'Test stand for internally cooled metal gears', presented at the International Conference on Gears 2019, Garching/Munich, Germany, 2019, vol. VDI-Berichte 2355, pp. 1263-1265.

[3] 'Selektives Lasersintern (SLS) Material | igus ${ }^{\circledR}$ '. [Online]. Available: 
https://www.igus.ch/3d-print-material/selektives-lasersintern-material. [Accessed: 17-Feb-2020].

[4] A. Gebhardt, Additive Fertigungsverfahren: Additive Manufacturing und 3DDrucken für Prototyping - Tooling - Produktion, 5th ed. München: Carl Hanser Verlag GmbH \& Co. KG, 2016.

[5] J. Roesler, 'Zur Tragfähigkeitssteigerung thermoplastischer Zahnräder mit Füllstoffen', Doctoral Thesis, Technische Universität Berlin, Fakultät V - Verkehrsund Maschinensysteme, Berlin, 2005.

[6] Verein Deutscher Ingenieure VDI, '2736-1: Thermoplastische Zahnräder Werkstoffe, Werkstoffauswahl, Herstellverfahren, Herstellgenauigkeit, Gestalten', Berlin: Beuth Verlag, 2014.

[7] H.-J. Dennig, S. Monn, and A. Vodermayer, 'Thermoplastic high performance composite gears', in 3rd International Conference on High Performance Plastic Gears 2019, Garching/Munich, Germany, 2019, vol. VDI-Berichte 2355, pp. 1279-1290.

[8] Verein Deutscher Ingenieure VDI, '2736-2: Thermoplastische Zahnräder Ermittlung von Tragfähigkeitskennwerten an Zahnrädern', Berlin: Beuth Verlag, 2013.

[9] P. Skawiński, P. Siemiński, and P. Błazucki, 'Applications of additive manufacturing (FDM method) in the manufacturing of gear', Mechanik, no. 12, pp. 976/173-976/179, Dec. 2015, doi: 10.17814/mechanik.2015.12.582.

[10] Stratasys, 'Datasheet PLA Filament', 2020. [Online]. Available: https://www.stratasys.com/de/materials/search/pla.

[11] Stratasys, 'Data sheet ABS Filament', 2020. [Online]. Available: https://www.stratasys.com/de/materials/search/abs.

[12] Markforged, 'Material Datasheet Composites - REV 3.2 - 9/9/2019'. [Online]. Available: http://static.markforged.com/downloads/composites-data-sheet.pdf. 